\title{
Generation Times of Individual Bacteria: Some Corroborative Measurements
}

\author{
By E. O. POWELL AND F. P. ERRINGTON \\ Microbiological Research Establishment, Porton Down, \\ Salisbury, Wiltshire
}

(Received 27 September 1962)

\begin{abstract}
SUMMARY
Measurements of individual generation times were carried out on three species of bacteria, each in two different growth media. They confirmed in every respect conclusions already reached about the broad features of the generation time pattern. In addition, they supported two important inferences the existing evidence for which was no more than suggestive: (i) complex media give rise to a greater dispersion of generation time than do simple media; (ii) there is positive association between the generation times of second cousins, i.e. organisms whose nearest common ancestor is three generations removed.
\end{abstract}

\section{INTRODUCTION}

The observations of bacterial generation times recorded in this paper were intended to supplement those of Powell (1958). We wished particularly to resolve doubts concerning two inferences, of some interest and importance, which were suggested but only weakly supported by Powell's data. These were (i) that the coefficient of variation of generation times is greater, the greater the chemical complexity of the growth medium; (ii) that the properties of a given organism affect the individual generation times of its progeny up to at least the third generation.

The experiments were conducted in the same way as Powell's (1958); the organisms were grown on a cellophane membrane in a culture chamber (Powell, 1956b) which permitted observation under phase-contrast illumination while the aerated growth medium was continuously circulated under the cellophane. A large number (800-900) of measurements of individual generation times were made for each combination of organism and medium. Perhaps as a result of increasing skill and experience it was found possible to maintain sensibly constant growth rate until overcrowding became intolerable, i.e. often up to six mean generation times. It was thus possible to obtain a much higher proportion of observations on complete sets of eight second cousins-the third generation progeny of single ancestors (' $C_{2}$-octads' Fig. 1). In addition, records were kept in such a way as to preserve the original topology of the family trees. It results from the repeated transverse binary fission of rod-like organisms that those belonging to any one generation from a common ancestor fall into a natural order, shown schematically in Fig. $1 \mathrm{~A}$, even though the spatial order actually realized may be altered through mechanical or temporal displacement (the same applies to Streptococcus; but Staphylococcus 
and Gaffkya, for example, give rise to more complex, though still definite, arrays). It may be suspected then, that the properties of an organism may be to some extent dependent on its position in the chain to which it belongs; for example, the cell wall of an ancestor (Fig. 1 A (a) and Fig. 3) may be for the most part transmitted to the terminal organisms of the chains into which it develops. Accordingly all observations were recorded in the form of trees (Fig. 1B) corresponding in their spatial order with the development of the organisms they represented.
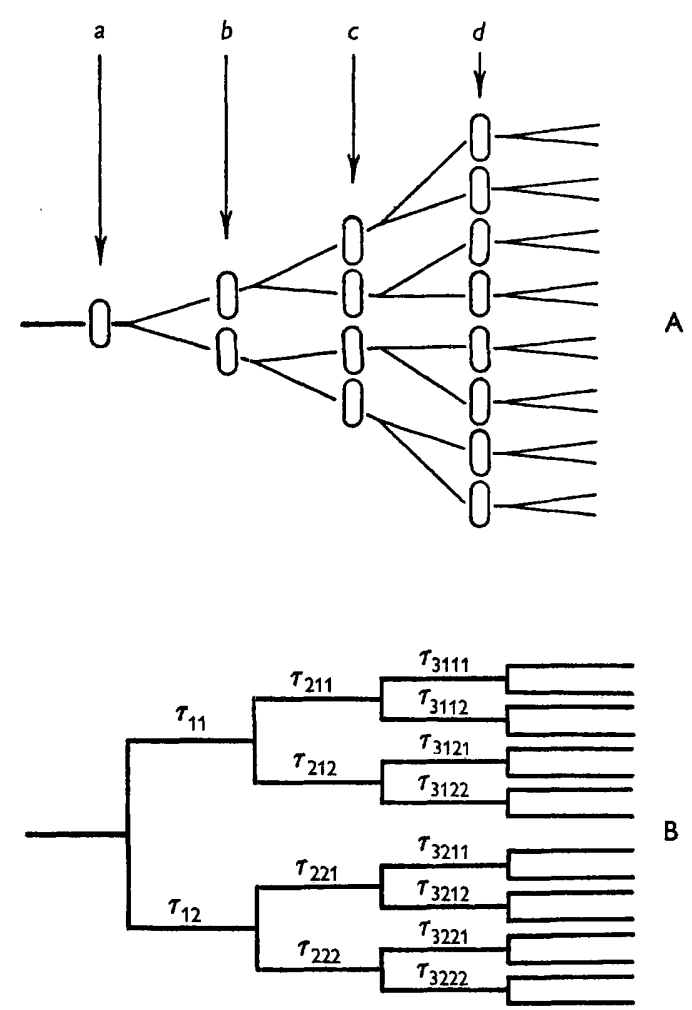

Fig. 1A. A typical family tree. The groups of organisms in each generation are referred to as: $a$, ancestor; $b, s$-dyad; $c, C_{1}$-tetrad; $d, C_{2}$-octad. Schematic: because of the dispersion of generation time not all the organisms in $c$ and $d$ are necessarily contemporaries. B. Method of recording results. The horizontal segments are labelled with the $\tau$ of the corresponding organisms in $\mathbf{A}$.

\section{ORGANISMS AND MEDIA}

Three species of organisms were used: one strain each of Pseudomonas aeruginosa, Proteus vulgaris and Escherichia coli. Previous experience had suggested that Proteus does not readily produce elongated swarming organisms on cellophane over a flowing medium (Powell, 1955), and in fact a rather crude test (Powell, 1958) showed that the growth rate was satisfactorily constant over the experimental periods.

Two series of experiments were carried out for each species, one with tryptic meat broth ('TMB') and one with a chemically defined medium (' $\mathrm{H} 12 \mathrm{P}$ '). The 
chemically defined medium was made up from 'Analar' chemicals and demineralized water in the following way:

Solution (i): $\mathrm{NaH}_{2} \mathrm{PO}_{4} \cdot 2 \mathrm{H}_{2} \mathrm{O}, 31 \mathrm{~g} .(0 \cdot 2 \mathrm{M})$; $\left(\mathrm{NH}_{4}\right)_{2} \mathrm{HPO}_{4}, 238 \mathrm{~g}$. (1.8 M); $\mathrm{K}_{2} \mathrm{SO}_{4}$, $70 \mathrm{~g} .(0 \cdot 4 \mathrm{M})$; water to 11 .

Solution (ii): Concentrated $\mathrm{HCl}, 50 \mathrm{ml} .(0.58 \mathrm{M}) ; \mathrm{MgO}, 10 \mathrm{~g} \cdot(0.25 \mathrm{M}) ; \mathrm{CaCO}_{3}$, 2 g. $(0.02 \mathrm{M}) ; \mathrm{FeCl}_{3} \cdot 6 \mathrm{H}_{2} \mathrm{O}, 5 \cdot 4 \mathrm{~g} . \quad(0.02 \mathrm{M}) ; \mathrm{ZnSO}_{4} .7 \mathrm{H}_{2} \mathrm{O}, \mathbf{1} \cdot 44 \mathrm{~g} . \quad(0.005 \mathrm{M})$; $\mathrm{MnSO}_{4} \cdot 4 \mathrm{H}_{2} \mathrm{O}, 1.11 \mathrm{~g} .(0.005 \mathrm{M}) ; \mathrm{CuSO}_{4} .5 \mathrm{H}_{2} \mathrm{O}, 0.25 \mathrm{~g} .(0.001 \mathrm{M}) ; \mathrm{CoSO}_{4} \cdot 7 \mathrm{H}_{2} \mathrm{O}$, 0.28 g. $(0.001 \mathrm{M}) ; \mathrm{H}_{3} \mathrm{BO}_{3}, 0.062$ g. $(0.001 \mathrm{M}) ; \mathrm{Na}_{2} \mathrm{MoO}_{4} / 2 \mathrm{H}_{2} \mathrm{O}, 0.49$ g. $(0.002 \mathrm{M})$; water to 11 .

Solutions (i) (50 ml.) and (ii) (5 ml.) were mixed, made up to 11 . with water and autoclaved.

Solution (iii): Citric acid, $4 \cdot 2$ g. $(0.02 \mathrm{M})$; glucose, $3 \cdot 6$ g. (0.02 M); L-glutamic acid, $2.94 \mathrm{~g}$. (0.02 M); succinic acid, $1 \cdot 18 \mathrm{~g}$. $(0.01 \mathrm{M})$; these components were mixed in a little water (ca. $50 \mathrm{ml}$.) and neutralized with $\mathrm{NaOH}$, then $\mathrm{Na}_{2} \mathrm{~S}_{2} \mathrm{O}_{3} .5 \mathrm{H}_{2} \mathrm{O}, \mathbf{1 \cdot 2 4} \mathrm{g}$. $(0 \cdot 005 \mathrm{M})$ was added.

This mixture was filtered, with sterility precautions, into 11 . of the previously autoclaved salt solution.

For the growth of Proteus vulgaris solution (iii) was fortified with $1 \mathrm{mg}$. of nicotinic acid (Medium ' $\mathrm{H} 12 \mathrm{P}^{*}$ ').

Of the addenda in solution (iii), the citric acid mainly served to prevent the precipitation of metal phosphates. The other substances had each been found to increase the growth rate of one or more of the organisms with which the medium had been tested.

Table 1. Synopsis of experiments

\begin{tabular}{|c|c|c|c|c|}
\hline $\begin{array}{c}\text { Series } \\
\text { reference } \\
\text { no. }\end{array}$ & Organism & Medium & $\begin{array}{c}\text { No. of } \\
\text { experiments }\end{array}$ & $\begin{array}{c}\text { Total no. of } \\
\text { generation } \\
\text { times }\end{array}$ \\
\hline Pa 1 & $\begin{array}{c}\text { Pseudomonas } \\
\text { aeruginosa }\end{array}$ & TMB & 29 & 963 \\
\hline $\mathbf{P a 2}$ & P. aeruginosa & H12P & 12 & 887 \\
\hline Pv 1 & Proteus vulgaris & TMB & 19 & 874 \\
\hline Pv 2 & $P$. vulgaris & H $12 P^{*}$ & 10 & 850 \\
\hline Ec 1 & Escherichia coli & TMB & 25 & 854 \\
\hline Ec2 2 & E. coli & H12P & 13 & 815 \\
\hline
\end{tabular}

Before a series of experiments was begun, the organism was subcultured at least three times on the chosen medium, and after the culture chamber had been inoculated, a period of incubation was allowed before any observations were made (Powell, 1958). All experiments were carried out at $35^{\circ}$. Generation times were recorded to the nearest $1 \mathrm{~min}$., but it should be understood that the personal error of estimation is probably greater than this-perhaps 2-5 min., depending on the growth rate. For the most part, observations were continued on the progeny of selected organisms up to an equal number of generations in every line of descent. When because of overcrowding it became necessary to break off observations on certain branches of a family, the decision to do so was taken in such a way as not to bias the observations in favour of short-lived organisms (cf. Powell 1955).

Table 1 gives a synopsis of the experiments undertaken. 


\section{ANALYSIS OF OBSERVATIONS}

In view of the similarity of the experimental conditions, it will not be necessary to repeat Powell's (1958) lengthy discussion of the effects of experimental error. But it is desirable to review one feature of our results which is in fact common to all extended investigations in this subject: the lack of statistical homogeneity in series of replicate experiments. It has invariably been found that analysis of variance applied to such series has disclosed a highly significant inter-experiment variance suggestive of imperfect replication. It is often obvious to inspection that the mean generation times in individual experiments differ much more than would be expected from the variances and sample sizes. Neither improvements in technique nor increase in sample size have mitigated the discrepancy. It seems therefore that the heterogeneity should be accepted as a genuine feature of the pattern of generation times. Powell (1958) explained it as a result of the association between generation times of closely related organisms, coupled (in his experiments, and the same applies to ours) with the method of selecting organisms for observation.

We subjected our results, series by series, to conventional two-way analyses of variance in order to obtain estimates of the 'true' (within-experiment) variance $\sigma_{\tau}^{2}$ of the generation times $(\tau)$ and of the between-experiment variance $\sigma_{E}^{2}$ supposedly introduced by imperfect replication. On the assumption that the coefficient of variation of $\tau$ is a stable property, not sensibly affected by minor changes in experimental conditions, the results of the analysis were used to compute corrected coefficients of variation $c_{0}$; if $\mathbf{a}, \sigma^{2}$, and $c$ are respectively the grand mean, variance and coefficient of variation in a given series of experiments, $c=\sigma / \mathbf{a}$; the variation of the mean from experiment to experiment introduces a coefficient of variation $c_{j}=\sigma_{E} / \mathbf{a} ;$ and (Powell, 1955)

$$
c_{0}^{2}=\left(c^{2}+1\right) /\left(c_{j}^{2}+1\right)-1
$$

(see Table 2). If we admit that the apparent inter-experiment variance is in part due to lack of reproducibility and in part contributed by a real property of the generation time distribution, we can say that the true coefficient of variation lies between $c$ and $c_{0}$, and similarly that any other parameter is likely to be over-corrected by an adjustment derived from the analysis of variance.

\section{Table 2. Estimates of variances}

Estimates of the apparent within-experiment $\left(\sigma_{\tau}^{2}\right)$ and between-experiment $\left(\sigma_{E}^{2}\right)$ variances, derived from 2-way analyses of variance, together with the crude $(c)$ and corrected $\left(c_{0}\right)$ coefficients of variation of $\tau$. The grand mean (a) and estimated variance $\left(\sigma^{2}\right)$ of the observations are also given. The coefficient of variation $\left(c_{j}\right)$ for the fluctuation of experiment means is used here and elsewhere in correcting other parameters. (Unit of time, 1 min.)

\begin{tabular}{|c|c|c|c|c|c|c|c|}
\hline Series & $\mathbf{a}$ & $\begin{array}{r}\text { Est. } \\
\sigma^{2}\end{array}$ & $\begin{array}{c}\text { Est. } \\
\sigma_{v}^{2}\end{array}$ & $\begin{array}{r}\text { Est. } \\
\sigma_{E}^{2}\end{array}$ & $c^{2}$ & $c^{2}$ & $c_{0}^{2}$ \\
\hline Pa 1 & $32 \cdot 22$ & $48 \cdot 11$ & $43 \cdot 30$ & 5.618 & $0 \cdot 04634$ & 0.005412 & 0.04071 \\
\hline Pa2 & $38 \cdot 86$ & $54 \cdot 29$ & 41.98 & $13 \cdot 66$ & 0.03594 & 0.009047 & 0.02665 \\
\hline Pv 1 & $19 \cdot 29$ & 20.54 & $19 \cdot 13$ & 1.593 & 0.05521 & $0 \cdot 004282$ & $0 \cdot 05071$ \\
\hline Pv2 & $43 \cdot 64$ & $55 \cdot 11$ & $52 \cdot 87$ & $2 \cdot 625$ & 0.02894 & 0.001378 & 0.02752 \\
\hline Ec 1 & $19 \cdot 79$ & $21 \cdot 50$ & $20 \cdot 60$ & $1 \cdot 064$ & $0 \cdot 05509$ & 0.002715 & $0 \cdot 05223$ \\
\hline Ec 2 & $29 \cdot 02$ & $27 \cdot 37$ & $24 \cdot 80$ & $1 \cdot 698$ & 0.03250 & 0.002017 & 0.03042 \\
\hline
\end{tabular}




\section{The distribution of generation times}

The foregoing remarks, added to a steadily accumulating general experience, suggest that the fitting of frequency functions to the pooled results of a series of experiments is less dubious than it seemed in the earlier days of the subject. It is still best, however, to regard any fitted function as a convenient description, merely useful for algebraic and statistical manipulation.

Kubitschek (1962), moved apparently by a not unusual prejudice in favour of the normal distribution, found that the distribution function of the reciprocal of the generation time gave a nearly linear plot on arithmetic-probability paper, but he gave no statistical test of the fit. Davies (1947) says of this procedure '... a fair straight line can be obtained with data which are far from normal . . a histogram gives a better idea of the shape of the distribution, and is less likely to lead to false conclusions'. Since Kubitschek himself found that his generation time measurements could be adequately fitted to a Pearson Type III distribution

$$
f(\tau)=\frac{\tau^{g-1} e^{-\tau / m}}{m^{g} \Gamma(g)}
$$

it follows that $\mathbf{1} / \tau$ must have been distributed approximately in a Pearson Type V, which is more skew than the corresponding Type III and in that respect less nearly normal. Since also the normal distribution is inappropriate because of its unlimited range, we see no reason to accord it any special place at this stage.

We therefore graduated our measurements by fitting three convenient singly terminated distributions:

(i) the Pearson Type III (Equation (2));

(ii) the Pearson Type V,

$$
f(\tau)=\frac{m^{g} \tau^{-g-1} e^{-m / \tau}}{\Gamma(g)}
$$

(iii) a distribution of intermediate form suggested by Ash and Powell (1962):

$$
f(\tau)=\frac{\tau^{-5 / 2} \exp \left\{-\frac{r}{2}\left(\frac{\tau}{m}+\frac{m}{\tau}\right)\right\}}{2 m^{-3 / 2} K_{3 / 2}(r)} .
$$

(Here $\boldsymbol{K}_{3 / 2}(r)$ is the modified Bessel function of the second kind. We refer to this frequency function, for convenience, as a ' $K$-distribution'). The parameters $g$ (in (2) and (3)) and $r$ (in (4)) are measures of intrinsic dispersion-functions of the coefficient of variation; $m$ is a scale parameter. The results of fitting by the method of maximum likelihood are shown in Table 3. Only for one series (Ec2) does none of the functions provide an adequate fit, and inspection of the figures suggests that this is due to a ragged histogram, presumably accidental (Fig. 2). The sample skewness and kurtosis (Table 4) for series Ec2 were not extreme.

In spite of the usually good fit so obtained, the sample skewness and kurtosis of each series corresponded to points in the Type IV area of the Pearsonian $\beta_{1}, \beta_{2}$ diagram (see, for example, Pearson, 1930). We ascribe the excessive kurtosis to the few observations of large $\tau$ in the upper tails of the distributions, which on account of the necessity for grouping do not greatly affect the values of $\chi^{2}$. It is at all events 
Table 3. Frequency function parameters and goodness of fit by the $\chi^{2}$ test

\begin{tabular}{|c|c|c|c|c|c|c|c|}
\hline & \multicolumn{6}{|c|}{ Series } \\
\hline & & $\mathbf{P a} 1$ & $\mathbf{P a} 2$ & Pv 1 & Pv 2 & Ec1 1 & Ec2 2 \\
\hline $\begin{array}{r}\text { Type III } \\
\text { (eq. (2)) }\end{array}$ & $\begin{array}{l}g \\
m \\
\chi^{2} \\
n \\
P\left(\chi^{2}\right)\end{array}$ & $\begin{array}{c}24 \cdot 3 \\
1 \cdot 32 \\
46 \cdot 3 \\
28 \\
0 \cdot 017\end{array}$ & $\begin{array}{c}29 \cdot 9 \\
1 \cdot 30 \\
49 \cdot 6 \\
29 \\
0 \cdot 010\end{array}$ & $\begin{array}{c}18 \cdot 0 \\
1 \cdot 07 \\
16 \cdot 9 \\
19 \\
0 \cdot 60\end{array}$ & $\begin{array}{c}35 \cdot 6 \\
1 \cdot 23 \\
28 \cdot 8 \\
30 \\
0 \cdot 53\end{array}$ & $\begin{array}{c}18 \cdot 0 \\
1 \cdot 10 \\
28 \cdot 2 \\
20 \\
0 \cdot 11\end{array}$ & $\begin{array}{c}31 \cdot 4 \\
0 \cdot 92 \\
53 \cdot 6 \\
22 \\
0 \cdot 000\end{array}$ \\
\hline $\begin{array}{c}\text { Type V } \\
\text { (eq. (3)) }\end{array}$ & $\begin{array}{l}g \\
m \\
\chi^{2} \\
n \\
P\left(\chi^{2}\right)\end{array}$ & $\begin{array}{c}25 \cdot 7 \\
797 \\
33 \cdot 5 \\
26 \\
0 \cdot 15\end{array}$ & $\begin{array}{c}31 \cdot 1 \\
1171 \\
26 \cdot 4 \\
28 \\
0 \cdot 55\end{array}$ & $\begin{array}{c}17 \cdot 1 \\
312 \\
40 \cdot 0 \\
19 \\
0 \cdot 003\end{array}$ & $\begin{array}{c}35 \cdot 0 \\
1483 \\
27 \cdot 9 \\
30 \\
0 \cdot 57\end{array}$ & $\begin{array}{c}14 \cdot 3 \\
266 \\
67 \cdot 9 \\
22 \\
0 \cdot 000\end{array}$ & $\begin{array}{c}29 \cdot 5 \\
827 \\
116 \cdot 5 \\
23 \\
0 \cdot 000\end{array}$ \\
\hline $\begin{array}{l}K \text {-distribu- } \\
\text { tion } \\
(\text { eq. (4)) }\end{array}$ & $\begin{array}{l}r \\
m \\
\chi^{2} \\
n \\
P\left(\chi^{2}\right)\end{array}$ & $\begin{array}{l}24 \cdot 3 \\
33 \cdot 5 \\
34 \cdot 1 \\
27 \\
0 \cdot 16\end{array}$ & $\begin{array}{c}29 \cdot 8 \\
40 \cdot 2 \\
34 \cdot 0 \\
28 \\
0 \cdot 20\end{array}$ & $\begin{array}{c}16 \cdot 8 \\
20 \cdot 4 \\
28 \cdot 5 \\
20 \\
0 \cdot 074\end{array}$ & $\begin{array}{c}34 \cdot 6 \\
44 \cdot 9 \\
25 \cdot 5 \\
29 \\
0 \cdot 65\end{array}$ & $\begin{array}{c}15 \cdot 6 \\
21 \cdot 1 \\
43 \cdot 6 \\
21 \\
0 \cdot 003\end{array}$ & $\begin{array}{c}29 \cdot 7 \\
30 \cdot 0 \\
77 \cdot 9 \\
22 \\
0 \cdot 000\end{array}$ \\
\hline
\end{tabular}

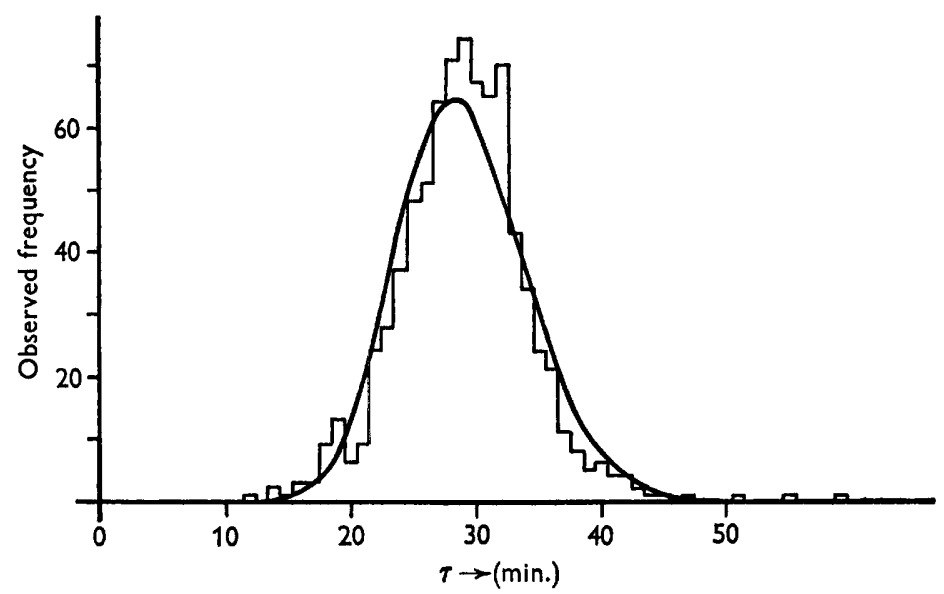

Fig. 2. A histogram of generation times in Escherichia coli (Series Ec2). The continuous line is a Pearson Type III distribution fitted by the method of maximum likelihood.

possible that the scattered values of $\gamma_{2}$ ('Table 4) are associated with the variability of the mean in replicate experiments.

Schaechter, Williamson, Hood \& Koch (1962) found that the skewness in small samples of generation time measurements was statistically non-significant. This is not surprising; but they did not look for a general tendency. Their belief that the skewness is negligible is in accordance with the Koch \& Schaechter (1962) model of the statistics of cell division, which predicts that the generation time distribution $f(\tau)$ will be symmetrical, or nearly so. We therefore think it worth while to describe a test of skewness which is independent of errors of replication.

It can be shown by the same method as was used by Powell (1955) in deriving 
equation (1), that if the true distribution of $\tau$ is symmetrical with coefficient of variation $c_{0}$, the observed third moment of $f(\tau)$ will be

$$
\mu_{3}=\mu_{3}(j)\left(3 c_{0}^{2}+1\right)+6 c_{0}^{2} c_{j}^{2} \mathbf{a}^{3}
$$

where $\mu_{3}(j)$ and $c_{j}$ are respectively the third moment and coefficient of variation of the distribution of the experiment means. Thus, the true third moment may be zero even if the observed skewness is positive, as it is always found to be in the pooled results.

In a positively skew distribution the median lies below the mean: in a group of small samples from such a distribution we should expect more than half to show an excess of observations in the range below the mean. Accordingly, in each of the experiments comprised in a series the number of observations falling above and below the experiment mean was counted; the corresponding signs of the difference (mean-median) are collected in Table 4. The numbers of experiments are too small to allow of attaining a high level of statistical significance in any one series, but the evidence is uniformly in favour of the hypothesis that the true median lies below the mean i.e. that the skewness is really positive. However, the test is much too crude to show that the Koch \& Schaechter model is untenable.

The general type of $K$-distribution proposed by Ash \& Powell (1962) contains an extra parameter in a factor $\tau^{g-1}$ instead of the fixed power $\tau^{-5 / 2}$ of (4), and it includes the Pearson Types III and V as limiting cases. It is thus adequate to describe the generation time distribution for most purposes.

Table 4. Sample values of the skewness, $\gamma_{1}$, and kurtosis, $\gamma_{2}$, of the crude distribution $f(\tau)$, together with the numbers of experiments classified according to the sign of (mean-median)

\begin{tabular}{lcccc} 
& & \multicolumn{2}{c}{$\begin{array}{c}\text { No. of experiments } \\
\text { in which the sign } \\
\text { of (mean-median) was }\end{array}$} \\
Series & Est. & Est. & Positive & Negative \\
Pa 1 & $\gamma_{1}$ & $\gamma_{2}$ & 18 & 7 \\
Pa2 & $1 \cdot 84$ & $10 \cdot 00$ & 10 & 2 \\
Pv1 & $1 \cdot 10$ & $2 \cdot 63$ & 10 & 5 \\
Pv2 & $0 \cdot 47$ & $0 \cdot 72$ & 7 & 3 \\
Ec1 & $0 \cdot 72$ & $1 \cdot 40$ & 15 & 4 \\
Ec2 & $0 \cdot 78$ & $\mathbf{2 \cdot 6 5}$ & 8 & 4
\end{tabular}

Non-viable organisms

Only six organisms could be fairly certainly classified as non-viable, among the 5200 observed. This confirms Powell's (1958) estimate, that the index of viability $\alpha$ is usually at least 0.99 in unhampered growth, but with so small a number no further generalization is possible.

\section{The dissymmetry of fission}

Málek has for long held that of the two so-called sisters arising from the fission of a single organism, one should properly be regarded as the progeny of the other (see e.g. Málek, 1955).

In general the two organisms have different generation times; there may be detectable differences in a few biochemical properties; one but not the other may 
occasionally turn out to be non-viable: such inequalities would not be remarkable in siblings of any species, and may well be random in character. But whether or not there is intrinsic inequality in the division of nuclear and cytoplasmic material, there is one respect in which fission is certainly unsymmetrical, namely in the manner of growth and inheritance of the cell wall. The main features of this process are most admirably described by Cole \& Hahn (1962); they dealt with only one species, but other evidence (e.g. Bisset, 1951), including the mode of inheritance of flagella (Stocker, 1956) and vital staining of cell walls with an optical bleach (Dr G. C. Ware, private communication) suggests the same general picture.

This picture is the same for all species that have been examined, apart from minor variations due to differences in relative timing of the component processes (Fig. 3). Cell-wall material is not uniformly secreted over the cell membrane, but

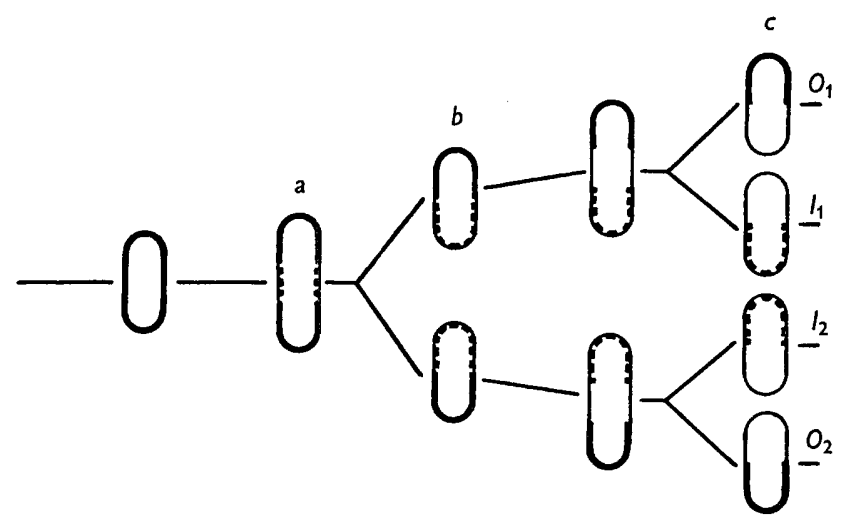

Fig. 3. Mode of inheritance of cell wall. During the growth of the ancestor, new cell wall is laid down in a central zone $(a)$. The two daughters $(b)$ carry partly new cell wall, partly cell wall which was already formed at the inception of the ancestor. In a $C_{1}$ tetrad $(c)$ the outer organisms $\left(O_{1}, O_{2}\right)$ inherit the older cell wall, the inner $\left(I_{1}, I_{2}\right)$ that which was laid down during the development of the ancestor.

is laid down in a zone overlying the site of an incipient fission (Fig. $3 a$ ). Each of a pair of sisters carries, on one half, cell wall already formed at the inception of the mother, on the other, cell wall laid down during the growth of the mother (Fig. $3 b$ ). Because of dissymmetry in the mother the two organisms at $(b)$ are not alike. It results that if the descent for two generations of a set of first cousins (' $C_{1}$-tetrad'; Fig. $3 c)$ is known, they can be labelled unambiguously as 'inner' $\left(I_{1}, I_{2}\right)$ and 'outer' $\left(O_{1}, O_{2}\right)$ organisms; the 'outer' organisms carry cell wall of a greater age than do the 'inner'. As the cell wall ages, it hardens; this can be shown directly in favourable cases (Powell, 1956 b). There is thus a possibility that the generation times of a pair of sisters of known descent might differ systematically according to their relative position in the family tree. The method of recording results which we have described enabled us to classify the organisms of most $S$-dyads as 'inner' $(I)$ or 'outer' $(O)$ in this sense.

For each series, the number of instances in which the generation time of the inner sister $\left(\tau_{I}\right)$ exceeded that of its outer sister $\left(\tau_{o}\right)$, and vice versa, were counted, with the result shown in Table 5. In five series the frequency of $\tau_{o}>\tau_{I}$ exceeded that of 
$\tau_{I}>\tau_{o}$, but reached significance (probability $\left.<0.05\right)$ in only two ( $\left.\mathrm{Pv} 1, \mathrm{Ec} 2\right)$. For the grand total, the difference $\left(\tau_{o}>\tau_{I}\right)-\left(\tau_{I}>\tau_{o}\right)$ was 129, about six times the standard deviation

$$
\sqrt{ }(2079) / 2=22 \cdot 8
$$

on the hypothesis of symmetry. The probability of such a discrepancy is about 0.005. Other methods of comparison were tried, e.g. the outermost organisms of $C_{2}$-octads were compared with the six inner organisms. Results of similar uniformity and significance were obtained.

There is thus good evidence that the generation time of an organism is in part determined by its position in the family tree, and so perhaps by the history of the cell wall which it bears. The effect is detectable only in large samples, however, and is probably due to nothing more than mechanical constraint.

Table 5. Generation times of inner $\left(\tau_{I}\right)$ and outer $\left(\tau_{0}\right)$ sisters compared

\begin{tabular}{|c|c|c|c|}
\hline \multirow[b]{2}{*}{ Series } & \multicolumn{2}{|c|}{ Instances of } & \multirow{2}{*}{$\begin{array}{c}\text { Total } \\
\text { instances }\end{array}$} \\
\hline & $\tau_{o}>\tau_{I}$ & $\tau_{I}>\tau_{o}$ & \\
\hline Pa 1 & 213 & 204 & 417 \\
\hline Pa2 & 165 & 169 & 334 \\
\hline Pvi & 194 & 145 & 339 \\
\hline Pv2 & 176 & 158 & 334 \\
\hline Ec 1 & 184 & 163 & 347 \\
\hline $\operatorname{Ec} 2$ & 172 & 136 & 308 \\
\hline Sums & 1104 & 975 & 2079 \\
\hline
\end{tabular}

The coefficient of variation of generation time

The crude $(c)$ and corrected $\left(c_{0}\right)$ coefficients of variation of $\tau$ are set out in Table 2 .

It can be seen that for each organism both the $c$ and the $c_{0}$ associated with the complex medium are greater than those associated with the chemically simpler defined medium. This finding adds considerable weight to Powell's (1958) data in support of his suggestion-an extension of Kendall's (1948) hypothesis-that 'the dispersion of generation time is dependent on the number of synthetic processes the organism is called upon to perform in order to convert pabulum into living matter'.

The range of media and species which have so far been investigated is very small, however. Clearly a much more expeditious method of determining $c$ is necessary if the range is to be greatly extended. An indication of such a method is to be found in Kendall's (1948) discovery, that under certain assumptions $c$ is approximately equal to the coefficient of variation of the number of organisms in colonies of the same age developed from single organisms. But it is not yet known to what extent Kendall's theorem may be falsified by the associations between generation times of related organisms.

\section{Correlations between generation times}

Five product-moment correlation coefficients were computed from the data (see Fig. 1B):

(i) Between the $\tau$ of mothers and daughters, $\rho\left(H_{1}\right)$. Typical pairs are $\tau_{11}, \tau_{211}$; $\tau_{11}, \tau_{212}$. 
(ii) Between the $\tau$ of grandmothers and granddaughters, $\rho\left(H_{2}\right)$. Typical pairs are $\tau_{11}, \tau_{31 a b}(a, b=1,2)$.

(iii) Between the $\tau$ of sisters, $\rho(S)$. A typical pair is $\tau_{11}, \tau_{12}$.

(iv) Between first cousins, $\bar{\mu}\left(C_{1}\right)$; in each $C_{1}$-tetrad the mean of the $S$-dyad on one side of the family was compared with the mean of that on the other. A typical pair is

$$
\frac{1}{2}\left(\tau_{211}+\tau_{212}\right), \frac{1}{2}\left(\tau_{221}+\tau_{222}\right) \text {. }
$$

(v) Between second cousins, $\bar{\rho}\left(C_{2}\right)$; in each $C_{2}$-octad the mean of the $C_{1}$-tetrad on one side of the family was compared with the mean of that on the other. A typical pair is

$$
\frac{1}{4} \Sigma \tau_{31 a b}, \frac{1}{4} \Sigma \tau_{32 a b} \quad(a, b=1,2) .
$$

The advantage of the special coefficients $\bar{\rho}\left(C_{1}\right), \bar{\rho}\left(C_{2}\right)$ is that they can show up a general similarity between the two branches of a family unobscured by the variations among the $\tau$ in each branch. Our larger sample sizes enabled us to prefer them to the less sensitive intra-class coefficients adopted by Powell (1958), in spite of their greater susceptibility to sampling errors when corrected for inter-experiment variation. (Powell used a slightly different notation for these coefficients, with dashed $C$ instead of dashed $\rho$; the present form is easier to print).

Table 6. Crude $(\rho)$ and corrected $\left(\rho_{0}\right)$ product-moment correlation coefficients between mothers and daughers $\left(H_{1}\right)$, grandmothers and granddaughters $\left(H_{2}\right)$, between sisters $(S)$, between first cousins $\left(C_{1}\right)$ and between second cousins $\left(C_{2}\right)$

\begin{tabular}{|c|c|c|c|c|c|c|}
\hline & & & & & & \\
\hline & $\mathbf{P a} 1$ & $\operatorname{Pa} 2$ & Pv 1 & Pv2 & Ec1 & Ec2 \\
\hline $\begin{array}{l}\rho\left(H_{1}\right) \\
n\end{array}$ & $\begin{array}{l}+0.125 \\
742\end{array}$ & $\underset{753}{+0 \cdot 108}$ & $\begin{array}{l}-0.017 \\
689\end{array}$ & $\begin{array}{l}-0 \cdot 090 \\
724\end{array}$ & $\begin{array}{l}-0 \cdot 198 \\
680\end{array}$ & $\begin{array}{l}+0.119 \\
674\end{array}$ \\
\hline $\begin{array}{l}\rho\left(\boldsymbol{H}_{2}\right) \\
n\end{array}$ & $\begin{array}{l}+0 \cdot 126 \\
370\end{array}$ & $\begin{array}{l}+0 \cdot 203 \\
500\end{array}$ & $\begin{array}{l}+0 \cdot 015 \\
288\end{array}$ & $\begin{array}{l}-0 \cdot 126 \\
436\end{array}$ & $\begin{array}{l}+0 \cdot 050 \\
393\end{array}$ & $\begin{array}{l}-0 \cdot 110 \\
427\end{array}$ \\
\hline $\begin{array}{l}\rho(S) \\
n\end{array}$ & $\begin{array}{l}+0.513 \\
470\end{array}$ & $\begin{array}{l}+0 \cdot 632 \\
433\end{array}$ & $\begin{array}{l}+0.596 \\
427\end{array}$ & $\begin{array}{l}+0.624 \\
417\end{array}$ & $\begin{array}{l}+0 \cdot 402 \\
397\end{array}$ & $\begin{array}{l}+0.478 \\
401\end{array}$ \\
\hline $\begin{array}{l}\vec{\rho}\left(C_{1}\right) \\
n\end{array}$ & $\begin{array}{l}+0 \cdot 499 \\
204\end{array}$ & $\begin{array}{l}+0.522 \\
178\end{array}$ & $\begin{array}{l}+0 \cdot 175 \\
177\end{array}$ & $\begin{array}{l}+0 \cdot 446 \\
180\end{array}$ & $\begin{array}{l}+0.317 \\
161\end{array}$ & $\begin{array}{l}+0.374 \\
177\end{array}$ \\
\hline $\begin{array}{l}\bar{\rho}\left(C_{2}\right) \\
n\end{array}$ & $\begin{array}{c}+0 \cdot 438 \\
58\end{array}$ & $\begin{array}{l}+0.554 \\
53\end{array}$ & $\begin{array}{l}+0 \cdot 349 \\
55\end{array}$ & $\begin{array}{c}+0.496 \\
61\end{array}$ & $\begin{array}{c}+0 \cdot 143 \\
43\end{array}$ & $\begin{array}{c}+0 \cdot 299 \\
57\end{array}$ \\
\hline $\begin{array}{l}\rho_{0}\left(H_{1}\right) \\
\rho_{0}\left(H_{2}\right) \\
\rho_{0}(S) \\
\bar{\rho}_{0}\left(C_{1}\right) \\
\bar{\rho}_{0}\left(C_{2}\right)\end{array}$ & $\begin{array}{l}+0.009 \\
+0.010 \\
+0.449 \\
+0.400 \\
+0.266\end{array}$ & $\begin{array}{l}-0.193 \\
-0.066 \\
+0.508 \\
+0.309 \\
+0.251\end{array}$ & $\begin{array}{l}-0.099 \\
-0.068 \\
+0.562 \\
+0.086 \\
+0.220\end{array}$ & $\begin{array}{l}-0.145 \\
-0.182 \\
+0.606 \\
+0.412 \\
+0.450\end{array}$ & $\begin{array}{r}-0.261 \\
+0.001 \\
+0.371 \\
+0.266 \\
+0.040\end{array}$ & $\begin{array}{r}+0.060 \\
-0.183 \\
+0.444 \\
+0.316 \\
+0.201\end{array}$ \\
\hline
\end{tabular}

Number of pairs of observations : $n$.

The values of $\rho\left(H_{1}\right)$ and $\rho(S)$ (Table 6) were comparable with previous experience: in spite of the high values of $\rho(S)$-near $0 \cdot 5-\rho\left(H_{1}\right)$ was nowhere strikingly different from zero. The individual values of $\rho\left(H_{1}\right)$ obviously differed among themselves, but no general pattern was discernible. The same was true of $\rho\left(H_{2}\right)$, and in particular it was not everywhere positive nor systematically nearer to 0 than $\rho\left(H_{1}\right)$ (cf. Fieller's suggestion in Powell, 1958). Corrected values of these three coefficients, $\rho_{0}(S), \rho_{0}\left(H_{1}\right), \rho_{0}\left(H_{2}\right)$ were obtained by application of Powell's (1958), formula, but 
no greater regularity appeared (Table 6). It must be admitted, then, that we can offer at present no quantitative description of the manner in which generation times are inherited.

That generation times are inherited in some sense is made evident by the correlations $\bar{\rho}\left(C_{1}\right), \bar{\rho}\left(C_{2}\right)$. The effect of inter-experiment variance on the presumptive true values is given by Powell; a transposition of his formulae yields :

$$
\begin{aligned}
& \bar{\rho}_{0}\left(C_{1}\right)=\bar{\rho}\left(C_{1}\right)-\left\{1-\bar{\rho}\left(C_{1}\right)\right\} \frac{2 c_{j}^{2}}{c^{2}\{1+\rho(S)\}-2 c_{j}^{2}}, \\
& \bar{\rho}_{0}\left(C_{2}\right)=\bar{\rho}\left(C_{2}\right)-\left\{1-\bar{\rho}\left(C_{2}\right)\right\} \frac{4 c_{j}^{2}}{c^{2}\{1+\rho(S)\}\left\{1+\bar{\rho}\left(C_{1}\right)\right\}-4 c_{j}^{2}} .
\end{aligned}
$$

Both the crude and corrected values (Table 6) were not only positive throughout, but surprisingly large in several cases. We can conclude that the influence of an ancestor is transmitted through at least three generations. The series of coefficients $\rho(S), \bar{\rho}\left(C_{1}\right), \bar{\rho}\left(C_{2}\right)$ diminish on the whole so slowly as to suggest that the two branches of the family tree stemming from a common ancestor retain their similarity for a long time, though this similarity is obscured by variability in the individual $\tau$.

By isolating single cells from large and small colonies of Escherichia coli, and allowing them to develop, Hughes (1955) inferred that growth rate could be inherited over many generations. Powell (1958) criticized Hughes on the ground that he had not taken sufficient account of the effect of the initial conditions on the development of colonies. While we still consider Powell's objection to be valid, our figures for the correlation coefficients tend to support Hughes's conclusion.

\section{DISCUSSION}

The general sense of the above results is such as uniformly to support earlier work on the pattern of generation times. In spite of the large sample sizes, they do not suggest any appreciable refinement of previous descriptions. In this section, therefore, we wish only to advance some remarks on the generation time distribution.

We shall assume that the proportion of non-viable organisms thrown off by a steadily growing culture is negligible, i.e. that the index of viability $(\alpha)$ is unity. The adjustments necessary when this assumption does not hold are indicated in Powell $(1956 a)$. We shall also assume that the correlation coefficients $\rho\left(H_{1}\right)$, $\rho\left(H_{2}\right)$ and similar coefficients of higher order are small enough not to affect the growth rate appreciably.

The integral defining the number growth rate, $\nu$, namely

$$
2 \int_{0}^{\infty} e^{-v \tau} f(\tau) d \tau=1,
$$

implies very little restriction on the nature of $f(\tau)$ beyond its definition as a frequency function:

$$
\int_{0}^{\infty} f(\tau) d \tau=1, \quad f(\tau) \geqslant 0
$$

The last equation in fact shows that the factor $e^{-\nu \tau}$ in (5) cannot be everywhere as much as unity, and therefore that $\nu$ must have a positive non-zero value. Thus even when a possibly finite proportion of non-viable organisms is excluded the mean and all higher moments of $f(\tau)$ can be infinite. An example will make this clear. 
Suppose that $\tau$ is distributed in a Pearson Type V (Eq. (3)). For this distribution the mean and variance are

$$
\mu_{1}^{\prime}=\frac{m}{g-1}, \quad \mu_{2}=\frac{m^{2}}{(g-1)^{2}(g-2)},
$$

and the growth rate is given by

$$
\nu^{g / 2} K_{g}\{2 \sqrt{ }(m \nu)\}=2^{-2} m^{-g / 2} \Gamma(g),
$$

where $K_{g}$ is the modified Bessel function of the second kind (Powell 1958). If $g$ is as small as 2 and if for convenience we take $m=1$, the appearance of the frequency function (Fig. 4) is not at all unusual, but while the mean is finite $\left(\mu_{1}^{\prime}=1\right)$, the variance and higher moments are infinite. The growth rate, so far from being near to $(\log 2) / \mu_{1}^{\prime}$ is about $50 \%$ greater $(\nu=1.03)$. This is a somewhat extreme example, but

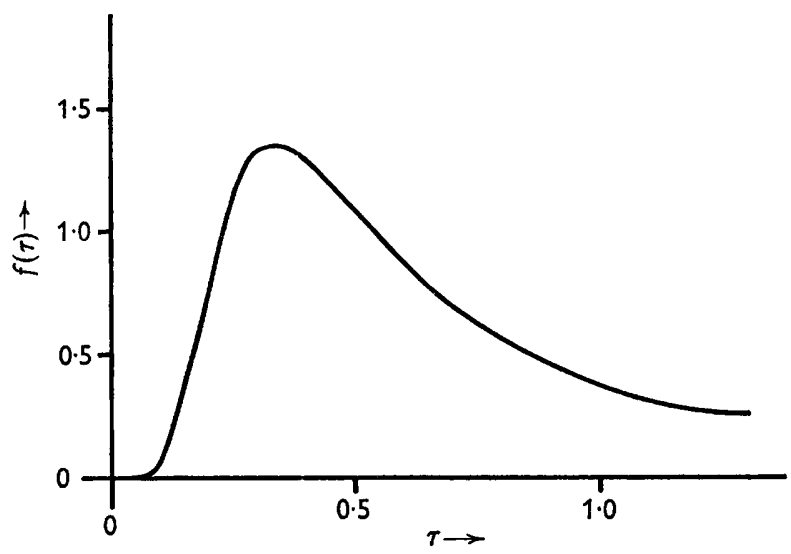

Fig. 4. Pearson Type V distribution with parameters $m=1, g=2$.

a re-examination of Powell's (1955) figures for Bacillus mycoides shows that they could be fairly well represented by a Type $\mathrm{V}$ distribution with $g$ near 5 . When $g=5$, the kurtosis $\gamma_{2}$ is 42 : the sampling variance of the variance is about 20 times that of a normal distribution with the same second moment. In most unicellular organisms, the frequency function is much more nearly symmetrical near the mode, but the upper tail of the distribution does not fall to zero as rapidly as is required by conventional functions which fit well over the range where the ordinates are large; and it is the tail which contributes so much to the higher moments.

Whatever explanation can be found to account for the variability of small samples (as evinced by analysis of variance), it may well be true that the whole population of $\tau$ ought to be represented by a frequency function whose higher moments are infinite. It is impossible to prove this by sampling alone, since all the moments of a finite sample are necessarily finite. Nevertheless, if in the futu rea particula function of this kind should be proposed, its definition will lead to inferences about sampling variance which will serve as a test of its truth. 


\section{REFERENCES}

Ash, R. \& Powell, E. O. (1962). A singly terminated frequency function with three parameters. Nature, Lond. 195, 770.

Bisset, K. A. (1951). The development of the surface structures in dividing bacteria J. gen. Microbiol. 5, 155.

Cole, R. M. \& Hahn, J. J. (1962). Cell wall replication in Streptococcus pyogenes. Science, 135, 722.

Davies, O. L. (1947). Statistical Methods in Research and Production. Edinburgh: Oliver and Boyd.

Hughes, W. H. (1955). The inheritance of differences in growth rate in Escherichia coli. J. gen. Microbiol. 12, 265.

Kendall, D. G. (1948). On the role of a variable generation time in the development of a stochastic birth process. Biometrika, 35, 316.

Koch, A. L. \& SchaEchter, M. (1962). A model for the statistics of the cell division process. J. gen. Microbiol. 29, 435.

Kubitscheк, H. E. (1962). Normal distribution of cell generation rate. Exp. Cell Res. 26, 439.

Málek, I. (1955). O množení a péstování mikroorganismů, zoláště bakterií. Praha: Nakladatelství československé akademie věd.

Pearson, K. (1930). Tables for Statisticians and Biometricians, 3rd ed. Cambridge University Press.

Powkls, E. O. (1955). Some features of the generation times of individual bacteria. Biometrika, 42, 16.

Powell, E. O. (1956 $a$ ) Growth rate and generation time of bacteria, with special reference to continuous culture. J. gen. Microbiol. 15, 492.

Powell, E. O. (1956b). An improved culture chamber for the study of living bacteria. J. R. micr. Soc. 75, 235.

Powell, E. O. (1958). An outline of the pattern of bacterial generation times. J. gen. Microbiol. 18, 382.

Schaechter, M., Wrlliamson, J. P., Hood, J. R. \& Koch, A. L. (1962). Growth cellular and nuclear division in some bacteria. J. gen. Microbiol. 29, 421.

STocker, B. A. D. (1956). Bacterial flagella: morphology, constitution and inheritance. Bacterial anatomy. Symp. Soc. gen. Microbiol. 6, 19. 